\title{
Changes in immunocompetent cells after interstitial laser thermotherapy of breast cancer
}

\author{
Kristin H. Haraldsdóttir · Kjell Ivarsson • \\ Karin Jansner · Unne Stenram · Karl-G. Tranberg
}

Received: 25 August 2010/Accepted: 15 February 2011/Published online: 13 March 2011

(C) The Author(s) 2011. This article is published with open access at Springerlink.com

\begin{abstract}
Background Local tumour destruction has been shown to give rise to changes in immunocompetent cells. The aim of this study was to describe the effect of interstitial laser thermotherapy (ILT) of breast carcinoma in the tumour and in regional lymph nodes.

Methods Seventeen women that underwent radical surgical excision after non-radical ILT were studied. ILT was performed at a steady-state temperature of $48^{\circ} \mathrm{C}$ for 30 min. Surgical excision was performed 12 (6-23) days after ILT. Six patients with breast cancer not treated with ILT before surgery served as controls. Immunohistological reactions were performed on core needle biopsies prior to treatment and on the excised specimens.

Results ILT resulted in more CD8 lymphocytes and CD68 macrophages within the tumour $(P<0.05$ and $P<0.01$, respectively) and higher counts of CD20 $(P<0.05), \mathrm{CD} 68(P<0.001)$ and $\mathrm{CD} 83(P<0.01)$ at the tumour border, when compared to pre-treatment values. In
\end{abstract}

\footnotetext{
K. H. Haraldsdóttir · K. Jansner · K.-G. Tranberg Department of Surgery, Lund University Hospital, 22185 Lund, Sweden

K. Ivarsson

Emergency Department, Lund University Hospital, 22185 Lund, Sweden

U. Stenram

Department of Pathology, Lund University Hospital,

22185 Lund, Sweden

K. H. Haraldsdóttir ( $₫)$

Department of Surgery, Landspitali University Hospital,

Hringbraut 101, Reykjavik, Iceland

e-mail: kristin.huld-haraldsdottir@med.lu.se
}

the control patients not receiving ILT, CD8 cells increased within the tumour after resection $(P<0.05)$. With the probable exception of CD25 Foxp3 cells, the presence of cancer in a lymph node influenced the findings in lymph nodes (examined for CD1a, CD25, Foxp3 CD25, CD83 cells). Thus, comparisons between ILT and control patients were restricted to patients without lymph node metastases. In these patients, ILT and resection were followed by a decrease in CD25 Foxp3 lymphocytes $(P<0.05)$, when compared to surgical resection alone.

Conclusions ILT induced changes in immunocompetent cells in patients with breast cancer. The stimulation of the immune system is an added feature of ILT in treatment of patients with breast cancer.

Keywords Breast cancer - Laser thermotherapy · Minimally invasive treatment . Tumour immunology

\section{Introduction}

Local minimally invasive methods have been evaluated for the treatment of tumours, and promising results have been published [1-5]. In breast cancer, surgery is still the standard treatment but improved diagnostic methods increase the possibilities for local destruction methods such as radiofrequency ablation, laser thermotherapy, cryotherapy and high-intensity focused ultrasound [6-12]. Advantages with these methods include minimal trauma, less immunosuppression than standard surgical resection and possibly the induction of a favourable immune response. Thus, the above-mentioned local therapies have been shown to be associated with changes in immunocompetent cells, providing indirect evidence that clinically important changes in the immune response may be obtained $[3-5,10,11]$. 
Interstitial laser thermotherapy (ILT) is attractive as a local destruction method since it gives precise control of the lesion size and, most importantly, provides a unique source of tumour antigens for the induction of anti-tumour immunity. ILT keeps the temperature in the range of $46-50^{\circ} \mathrm{C}$ at the tumour border, which causes tumour necrosis at the same time as the temperature is below the threshold for coagulation of proteins and thus tumour antigens. The necrosis develops within a time range of hours to a few days $[13,14]$ during which time uncoagulated and undestroyed tumour antigens can be exposed to the immune system. Furthermore, at this temperature level, tumour blood flow is not abolished [15].

In a rat liver tumour model, we have demonstrated that ILT (a) is superior to surgical resection, (b) gives a strong rejection immunity associated with an immune cellular response of tumour-infiltrating macrophages and CD8+ lymphocytes, (c) results in pronounced suppression of the growth of a simultaneous untreated tumour (distant bystander effect), (d) produces an increased antitumour lymphocyte proliferative response in tumourdraining and systemic lymph nodes and spleen and (e) results in increased HSP70 immunoreactivity in tumours and tumour-infiltrating macrophages [16-20]. Isbert et al. confirmed some of these findings showing an enhanced cellular immune response and a distant bystander effect after laser-induced thermotherapy [21].

To summarize, experimental studies have shown that laser-induced thermotherapy can induce immunity that eradicates minimal residual disease and prevents metastatic spread [20-22]. In the clinical situation, we have shown a distant bystander effect after laser thermotherapy in a patient with malignant melanoma [20].

The aim of this study was to find out if ILT of breast carcinoma induces changes in relevant immunocompetent cells (B cells, several T cells, dendritic cells, macrophages) in the tumour and in regional lymph nodes.

\section{Materials and methods}

\section{Patients}

In a previous study, we reported on 24 patients treated with ILT under local anaesthesia. The characteristics and workup of these patients were described in detail in a previous paper [7]. Seventeen of these patients had a 1-98\% tumour necrosis (mean 29\%) on pathological examination and are included in this study. Explanations for the wide range of tumour necrosis included the inclusion of some relatively large tumours and underestimation of tumour size by mammography and ultrasound [7].
Table 1 Clinical characteristics

\begin{tabular}{lll}
\hline & $\begin{array}{l}\text { ILT patients } \\
(n=17)\end{array}$ & $\begin{array}{l}\text { Control patients } \\
(n=6)\end{array}$ \\
\hline $\begin{array}{l}\text { Tumour size, mm } \\
\text { Ultrasound }\end{array}$ & $13(5.3-35)$ & $11(8-14)$ \\
$\quad$ Microscopic & $20(7-55)$ & $13(9-19)$ \\
Pathological diagnosis D/L/LD ${ }^{\mathrm{a}}$ & $9 / 7 / 1$ & $5 / 1 / 0$ \\
Tumour necrosis, \% & $29(1-98)$ & - \\
Lymph node metastases, Y/N $^{\text {ER/PR }}$ & $7 / 10$ & $1 / 5$ \\
Histological grading I/II/III & $15 / 12$ & $4 / 5$ \\
\hline
\end{tabular}

$D$ ductal carcinoma, $L$ lobular carcinoma, $L D$ lobular ductal carcinoma

a Two ILT and one control patient were negative for both ER and PR

b The two ILT patients who were negative for both ER and PR had grade II and III

Main clinical characteristics in this study are summarized in Table 1. None of the patients was taking steroids, cytostatics or other immune suppressive drugs. The patients' age range was 39-73 (mean 57). The diagnosis was invasive ductal carcinoma in nine patients, a lobular carcinoma in 7 and lobular ductal cancer in 1 . Average tumour diameter was $13 \mathrm{~mm}$ on ultrasound (5.3-35). Seven of the ILT patients, and one of the control patients, had axillary lymph node metastases (Table 1).

Treatment was carried out with a system consisting of a 805-nm diode laser (Diomed 25, Diomed, Cambridge, UK) and a temperature feedback control unit interfaced with the laser, as described previously [7]. A $600 \mu \mathrm{m}$ diameter flexible bare fibre housed in a polyvinyl sheet (D-6065, Diomed) was used to deliver the laser light interstitially. The temperature feedback control unit consisted of a personal computer, an automatic thermometry system (ATS-100, Lund Science, Lund, Sweden) and a thermistor probe (Aditus Medical Science AB, Lund, Sweden) inserted into a steel cannula (outer diameter $0.8 \mathrm{~mm}$ ). An optical beam splitter (Diomed) was used, when the treatment was performed with more than one fibre. Treatment was performed at a steady-state target temperature of $48^{\circ} \mathrm{C}$ for $30 \mathrm{~min}$, and the output laser power (maximum power was $3 \mathrm{~W}$ per fibre) was stepwise regulated to keep the treatment temperature stable.

Six patients, aged 43-76 (mean 59) years, receiving surgical resection only served as controls.

They were all considered for ILT but this was not performed because we could not accurately define the tumour border with pre-treatment ultrasound. One of these patients had invasive lobular cancer and five had invasive ductal cancer. Tumour size was 9-19 mm (mean $13 \mathrm{~mm}$ ). 
The study was approved by the local ethics committee and informed verbal and written consent was obtained in all patients.

\section{Pathological examination}

After palpation of the resected specimen, a section was cut through the middle of the tumour. Sections of $5-10 \mathrm{~mm}$ were cut from the fascia through the whole specimen perpendicular to and down to the skin. Tumour size and resection margins were noted and measured. The slices, still adherent to the skin, were fixed in $6 \%$ formaldehyde for 24-72 h. Core biopsies, with 18 or 16 gauge needles, and lymph nodes were also fixed for 24-72 h. The large slices were embedded in paraffin and cut, due to thickness, on one or two levels and stained with haematoxylin-eosin.

Immunohistological methods

All immunohistological reactions were performed on paraffin-fixed sections. From the large blocks of resected cancer, vital tumour areas with a few $\mathrm{mm}$ of surrounding tissue, slightly more than $1 \times 1 \mathrm{~cm}$, were chosen. The entire needle biopsies and sections from the lymph nodes were also used.

For single immunohistochemistry, the reactions were performed in an automatic immunostainer TechMate 500 (Ventana BioTech Systems, Tucson, AZ, USA) with Dako ChemMate Detection kit peroxidase/DAB+, giving a brown colour (Dako A/S, Glostrup, Denmark). They were performed with antibodies against CD1a, an antigen characterizing one type of immature dendritic cells (diluted 1:50, Dako, Glostrup, Denmark), CD4, a $T$ helper cell antigen (1:100, Novocastra, Newcastle, UK), CD8, a $T$ cytotoxic cell antigen (1:20, Dako), CD20, a $B$ cell antigen (1:2,000, Dako), CD25, the interleukin-2 receptor (1:100, Novocastra), CD57, an NK cell antigen (1:100, Novocastra), CD68, a macrophage antigen (1:20, Dako), CD83, a mature dendritic cell antigen (1:20, Novocastra), CD94, an NK cell antigen (1:20, Immunotech, Marseille, France), granzyme B, an antigen for perforin and granzyme B present in some cytotoxic T cells and NK cells (1:50, Dako), Foxp3, an antigen for forkhead/winged helix family of transcription factors $(1: 100,236 \mathrm{~A} / \mathrm{E} 7$, eBioscience, San Diego, USA). The antibody against the oestrogen receptor alfa was Dako clone 1D5 (diluted 1:35) and against the progesterone receptor Dako clone PgR 636 (1:150). For these two antibodies, the Dako DAB kit K5001 was used. The background staining was done with Mayer's haematoxylin.

Double staining immunohistochemical reactions were performed for CD25+ Foxp3+. The double staining was made in DakoCytomation Autostainer (Dako, Glostrup, Denmark). We used Envision G/2 Doublestain System (1:100 for both antibodies, Dako code K5361) where DAB, brown colour was used for Foxp3 and permanent red was used for CD25.

Tissue analysis

Photos of the immunohistological reactions were taken of vital tumour at the tumour border and in the interior of the cancers using a standard light microscope and a $10 \times$ objective (Bx-60, Olympus, Tokyo, Japan). The tumour border photos were taken with the tumour edge at the middle of the photo, meaning that half of the photo was tumour and the other half benign tissue outside the tumour. In that way, hot spots of lymphocytes, often found around lymphatic vessels just outside the tumour, were included in the figures of the tumour border. Results labelled as "within the tumour" do not include parts photoed as tumour border. We tried to get 20 photos at the edge and 20 in the interior of the cancers, but that was often not possible and especially not in the core biopsies. The median number of photos taken in the core biopsies was 4 (range 1-10) at the border of the tumour and $9(1-36)$ within the tumour. The number of photos taken of the vital tumour after ILT was 19 (3-42) at the edge and 17 (2-46) within. Representative photos were taken of lymph nodes with and without cancer.

Immunohistological reactions were considered positive only if the cell nucleus was seen. We recorded the distribution of labelled cells between the cancer nests, the stroma within the cancer and the benign tissue just outside the cancer. In the lymph nodes, the visual field with the highest number of positive cells ("hot spot") was used for counting.

The reason for using the "hot spot" method for counting cells in lymph nodes was the fact that many visual fields contained zero or very few positive cells. Counting of CD4+, CD20+, CD8+ and CD68+ cells in lymph nodes was not possible because of the extreme amount of positive cells. The average number of cells per visual field was reported for core biopsies and for resected tumours. We used the "hot spot" method also for the tumour specimens and the results did not differ (data not shown).

\section{Computerized digital analysis}

For computerized digital analysis, pictures were scanned and captured with a three-colour charge in order to facilitate interpretation and quantification of findings [16]. The images were saved in TIFF (Tagged Image File Format) format for analysis with Image-Pro Plus 4.5 software 
(Media Cybernetics; Silver Spring, MD). This software was used for counting the cells for all antibodies except CD68+ and CD25+ Foxp3+ cells. These were marked as the others but then counted manually. The reason for the individual counting of CD68+ cells was that it enabled us to exclude $\mathrm{CD} 68+$ (myo)fibroblasts. A few slender (myo)fibroblasts were positive in the CD8+ reaction but it was possible to choose a colour span so that the program could identify only CD8+ cells and not (myo)fibroblasts. CD25+ Foxp3+ cells were counted individually in order to be able to discriminate between double-stained CD25+ Foxp3+ cells and single-stained CD25+ or Foxp3+ lymphocytes.

Image-Pro Plus was also used to calculate the stained area $\left(\mu \mathrm{m}^{2}\right)$ and the Integrated Optical Density (IOD) (area $\times$ average density) for the different colours in the tumour tissue [16]. Area and IOD calculations confirmed the cell counting results but did not give any new or disagreeing information (data not shown).

\section{Statistical analysis}

Each patient was its own control, that is, we used the difference in number of cells for the various antibodies between the core biopsy and the resected tissue. Statistical significance of these differences was determined by the paired $t$ test, and Student's $t$ test was used for comparing ILT patients with the control group. A $P$-value of $<0.05$ was considered significant.

\section{Results}

There was a great variation in the density of immunocompetent cells between patients and in the tumour specimens from the same patient, both in ILT and control patients.

CD4+ and CD20+ cells were mostly found in the benign breast tissue outside the cancers and occasionally within the cancer stroma when the stroma was rich or, occasionally, between benign glandular cells when such cells were found within the cancers. CD8+ cells were found at the tumour border and also within the tumour, usually in the stroma between the cancer nests and in some cases also within the cancer nests (Fig. 1). Other cell types were mostly found in the stroma between cancer nests and rarely in the benign tissue at the tumour border.

Counts for the NK cell markers CD57 and, especially, CD94 were low and showed little variation between groups. This was also true for granzyme B. As a consequence, data for these cells are not shown. A few cancer cells were Foxp3+ positive (data not shown).

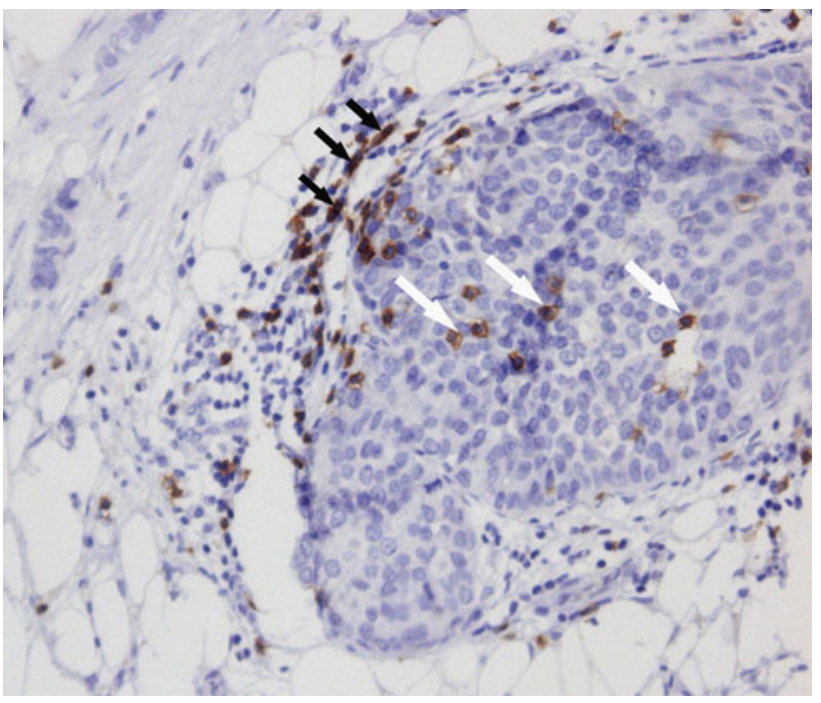

Fig. 1 Cytotoxic $T$ cells (CD8, brown colour) at the tumour border ( $\times 10$ objective). Positive cells are seen at the border in the stroma and also within the cancer nests (exemplified by white arrows). A few (myo)fibroblasts are also positive (exemplified by black arrows)

Tumour border

Figure 2 summarizes the findings at the tumour border and compares the cell densities before and after laser treatment. The predominant cell types were $\mathrm{CD} 8+, \mathrm{CD} 20+$ and CD68 + cells (Fig. 3). Significant increases in the resected tumour after ILT, when compared to the pre-treatment core biopsies, were observed for CD20 $+(P<0.05)$, CD68+ $(P<0.001)$ and CD83+ $(P<0.01)$ cells. A few patients had many CD68+ macrophages before ILT and showed no or little change in number after ILT. This was true also for CD68+ cells within the tumour. There was a tendency for CD8+ cells to be increased after laser treatment $(P=0.12)$. The CD8+/CD4+ ratio was not significantly increased after ILT when compared to pre-treatment biopsies $(P=0.20)$.

There were no significant differences between pre- and postoperative cell counts in control patients receiving surgery only (Table 2). Cell counts in resected specimens in control (surgery alone) and laser-treated patients were similar (Fig. 2; Table 2).

\section{Within tumour}

Largely, CD8+ and CD68+ cells were found within the cancers. The densities of CD8 and CD68 + cells were significantly larger after ILT than in the pre-treatment biopsies (Fig. 4; $P<0.05$ and $P<0.01$, respectively). There was no significant increase in the CD8+/CD4+ ratio after ILT. The number of CD25+ cells tended to be larger and the number of CD25+ Foxp3+ cells smaller, after 


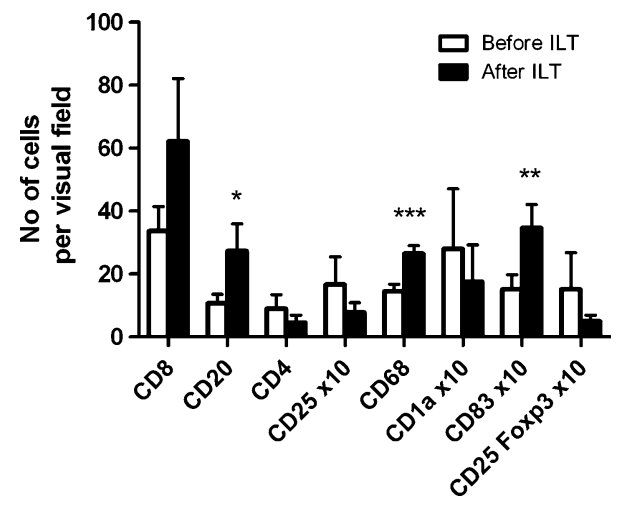

Fig. 2 Findings at the tumour border. Comparison of cell densities before and after interstitial laser thermotherapy (ILT). Paired $t$ test: $* P<0.05, * * P<0.01, * * * P<0.001$

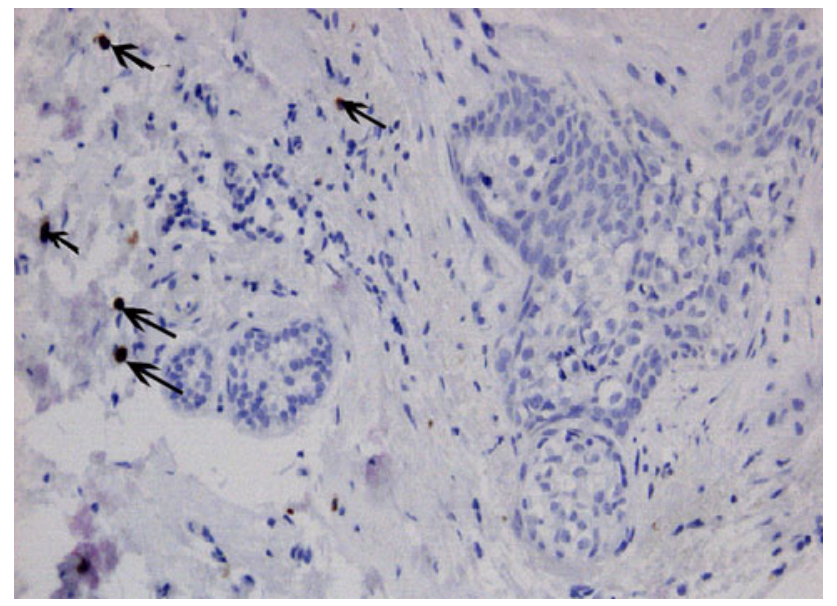

Fig. 3 Mature dendritic cells (CD83, brown colour) at the irregular tumour border to the left $(\times 10$ objective $)$. Positive cells are seen at the border in the stroma (arrows)

ILT but not significantly $(P=0.16$ and $P=0.20$, respectively).

In the control patients, i.e. patients not submitted to ILT, the number of $\mathrm{CD} 8+$ cells was larger after than before surgery (Table $2, P<0.05$ ). Values for $\mathrm{CD} 25+, \mathrm{CD} 68+$, granzyme $\mathrm{B}+$ and $\mathrm{CD} 25+$ Foxp3 + cells were of similar magnitude before and after surgery (Table 2). CD68+ counts were larger after ILT than after surgery alone (Fig. 4; Table 2; $P<0.05$ ).

\section{Lymph nodes}

As a rule, the number of immunocompetent cells in lymph nodes correlated with the presence or absence of lymph node metastases. The influence was obvious for the lymph nodes containing cancer when compared to lymph nodes in metastasis-free patients but there was a strong trend also when comparison was made between metastasisfree and metastasis-containing lymph nodes in patients
Table 2 Pre-and postoperative tumour findings in controls (patients receiving surgery only) $(n=6)$

\begin{tabular}{lcclll}
\hline & \multicolumn{2}{l}{ Tumour border } & & \multicolumn{2}{l}{ Within tumour } \\
\cline { 2 - 3 } \cline { 5 - 6 } \cline { 5 - 6 } & Preoperative & Postoperative & & Preoperative & Postoperative \\
\hline CD8 & $38.0 \pm 16.1$ & $47.1 \pm 12.1$ & & $17.3 \pm 6.2$ & $24.1 \pm 7.9^{*}$ \\
CD20 & $18.9 \pm 11.4$ & $26.2 \pm 7.4$ & & ND & ND \\
CD4 & $14.1 \pm 6.9$ & $19.3 \pm 11.5$ & & ND & ND \\
CD25 & $1.8 \pm 0.9$ & $1.0 \pm 0.5$ & & $0.79 \pm 0.40$ & $0.75 \pm 0.32$ \\
CD68 & $19.3 \pm 5.3$ & $18.6 \pm 2.8$ & & $11.5 \pm 2.3$ & $12.3 \pm 2.4$ \\
CD83 & $2.2 \pm 0.9$ & $2.5 \pm 0.8$ & & ND & ND \\
Granzyme & $0.40 \pm 0.21$ & $0.16 \pm 0.04$ & & $0.14 \pm 0.05$ & $0.05 \pm 0.01$ \\
$\quad B$ & & & & \\
CD25 & $1.9 \pm 0.9$ & $0.51 \pm 0.16$ & $1.08 \pm 0.17$ & $1.15 \pm 1.15$ \\
Foxp3 & & & & \\
\hline
\end{tabular}

$N D$ not done

$* P<0.05$ for comparison of pre- and postoperative levels

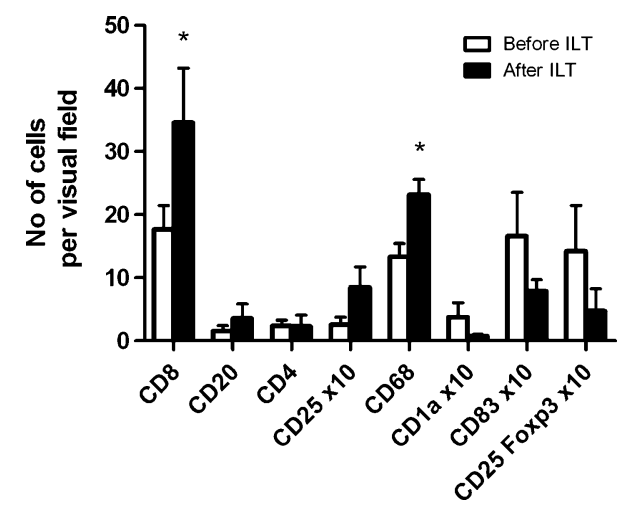

Fig. 4 Cell densities within the tumour before and after interstitial laser thermotherapy (ILT). Paired $t$ test: $* P<0.05$

with lymph node metastases (Table 3 ). In order to try to find possible effects of ILT on these cells, we therefore had to restrict the comparison between ILT and control patients to patients without lymph node metastases, in laser-treated and control patients (Fig. 5). This was done also for CD25+ Foxp3+ lymphocytes (Fig. 6), although it may be mentioned that these cells did not appear to follow the general pattern and that the presence of cancer in a lymph node had no, or little, influence on the number of $\mathrm{CD} 25+$ Foxp3+ cells (Table 3 ).

Comparison between ILT \pm resection and resection alone. When compared to surgical resection only, ILT and resection were followed by a lower number of $\mathrm{CD} 25+$ Foxp3+ lymphocytes (Fig. 5; $P<0.05$ ). Also, in patients without lymph node metastases, ILT was followed by a non-significant increase in $\mathrm{CD} 1 \mathrm{a}+(P=0.15)$ and a nonsignificant decrease in $\mathrm{CD} 25+(P=0.20)$.

Influence of lymph node metastasis (laser-treated patients). Cancer-free lymph nodes in patients with lymph 
Table 3 Immunocompetent cells in regional lymph nodes-influence of lymph node metastases in laser-treated patients

\begin{tabular}{|c|c|c|c|c|c|}
\hline & CD1a & CD83 & $\mathrm{CD} 25$ & CD25 Foxp3 & Granzyme B \\
\hline I. Patients without lymph node metastases & $63.8 \pm 13.7$ & $37.7 \pm 7.4$ & $41.7 \pm 9.0$ & $15.1 \pm 3.8$ & $20.1 \pm 8.6$ \\
\hline II. Patients with lymph node metastases-lymph nodes with tumour & $3.8 \pm 0.5$ & $4.6 \pm 2.9$ & $17.8 \pm 7.4$ & $14.7 \pm 5.0$ & $6.1 \pm 3.3$ \\
\hline Comparison with (I) metastases-free patients $(P)$ & $<0.01$ & $<0.01$ & 0.11 & 0.94 & 0.26 \\
\hline III. Patients with lymph node metastases-lymph nodes without tumour & $48.3 \pm 20.8$ & $43.4 \pm 19.0$ & $43.2 \pm 11.5$ & $7.3 \pm 2.4$ & $19.1 \pm 6.2$ \\
\hline Comparison with (II) tumour-free nodes in patients with metastases $(P)$ & 0.06 & 0.06 & 0.09 & 0.22 & 0.09 \\
\hline
\end{tabular}

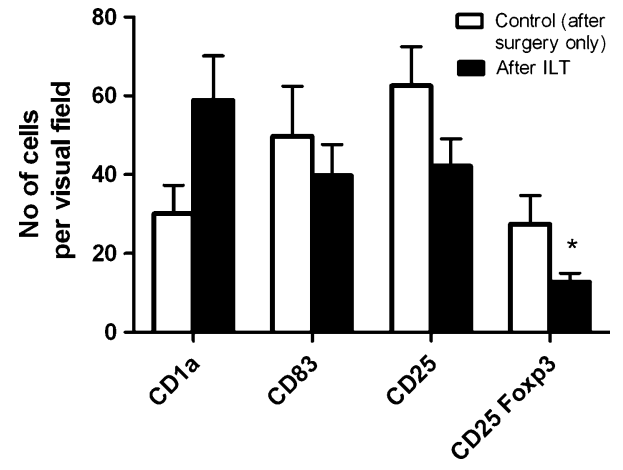

Fig. 5 Comparison of cell densities in regional lymph nodes after interstitial laser thermotherapy (ILT) and in controls (surgical resection only). Data after ILT represent findings in metastasis-free lymph nodes. Statistical comparison between ILT and controls was performed using only metastasis-free lymph nodes due to the influence of metastatic growth (Table 3). Students' $t$ test: $* P<0.05$

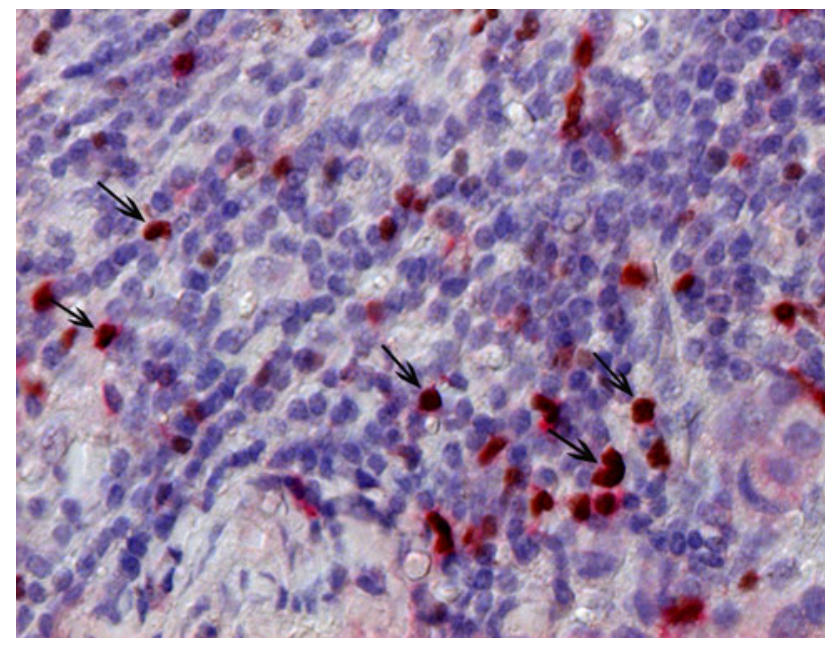

Fig. 6 CD25+/Foxp3+ cells (CD25+ red colour, Foxp3+ brown colour) (exemplified by arrows) in a lymph node ( $20 \times$ objective). Cells stained red only represent CD25+ lymphocytes

node metastases contained similar numbers of $\mathrm{CD} 1 \mathrm{a}+$, CD83+, CD25+ and granzyme B + cells as lymph nodes in metastases-free patients (Fig. 5; Table 3).

Cancer-containing lymph nodes had lower numbers of $\mathrm{CD} 1 \mathrm{a}+$ and CD83+ dendritic cells than lymph nodes in patients without nodal metastases (Table 3; $P<0.01$ in both cases). Also, there was a trend towards lower counts of $\mathrm{CD} 25+(P=0.11)$ in cancer-containing lymph nodes than in lymph nodes in patients without lymph node metastases.

In patients with lymph node metastases, there were no significant differences between lymph nodes containing cancer and cancer-free lymph nodes (Table 3 ). However, there were strong trends towards decreased counts of $\mathrm{CD} 1 \mathrm{a}+(P=0.06), \mathrm{CD} 83+(P=0.06), \mathrm{CD} 25+(P=$ $0.09)$ and granzyme $\mathrm{B}+$ cells $(P=0.09)$ in lymph nodes containing cancer.

\section{Discussion}

Undesirable effects of surgery include shedding of tumour cells into the circulation and the operative field, release of growth factors and immunosuppression [18]. In breast cancer, ILT should be of interest because it (a) can ablate a tumour without causing immunosuppression, (b) can improve the presentation of tumour antigens-inefficient antigen presentation limits the immune response to cancer [23] — which may induce or enhance anti-tumour immunity and (c) can be used in combination with surgical resection and immunomodulating drugs.

The microenvironment of cancer has become appreciated as an important factor in cancer immunology. Most cancers have few immunocompetent cells, and most tumour-associated antigens are self-antigens and only a few are tumour specific [24]. T cells are hypofunctional and need to be activated for effective immune responses, for instance, by an acute inflammatory reaction induced by cell death $[25,26]$. Changes induced by ILT may have positive effects on tumour immunogenicity not only by providing a source of tumour antigens but also by producing changes in the microenvironment.

In the present study, there was a large variation in the density of immunocompetent cells, both between patients and between different tumour areas within the same patient. We used intraindividual paired comparisons to deal with the variation between individuals and computerized digital analysis to diminish the effect of variations within the same tumour. Nevertheless, it should be pointed out 
that multiple testing in a relatively low number of patients carries the risk of obtaining falsely positive findings.

The number of immune infiltrating cells before treatment at the tumour border in the laser-treated patients and in the control patients was similar, as seen by comparing data in Figs. 2 and 4 (laser-treated patients) with data in Table 2 (control patients). Thus, it does not appear that difficulty to visualize the tumour border on ultrasound indicated a factor correlating with the number of immune infiltrating cells.

Mature and immature dendritic cells (CD83+ and CD1a+ cells)

Dendritic cells are important antigen-presenting cells (APCs) whose role is to capture and process antigen via the MHC-II pathway for presentation to CD4+ $T$ cells. Dendritic cells are present in very low numbers in normal breast tissue and their presence in malignant breast tumours is associated with improved prognosis [27-29]. Bell et al. [27] described that immature dendritic cells (CD1a+) are found within the tumour and that mature dendritic cells $(\mathrm{CD} 83+)$ are present at the tumour border and suggested that this reflects an ongoing immune response.

In the present study, there was no significant difference in the number of CD1a+ cells after ILT within the tumour or at the tumour border. Mature dendritic cells (CD83+) were significantly increased at the tumour border after ILT (Figs. 2, 3). An increased number of CD83+ cells at the tumour border have been reported to be a positive prognostic factor both in breast cancer [29] and metastatic liver tumours from colorectal cancer [30]. We have shown [16] that ILT induces increased expression of HSP70 in tumour cells and this seems to be a likely explanation for the induction of mature CD83+ dendritic cells after ILT [31].

In the lymph nodes, there was a trend towards an increased number of CD1a+ cells after ILT in patients without lymph node metastases (Fig. 5; $P=0.15$ ). Lymph nodes with cancer had low counts of CD1a+ and CD83+ (Table 3), both when compared to lymph nodes in patients without lymph node metastases $(P<0.01$ in both cases $)$ and when compared to negative lymph nodes in patients with positive nodes ( $P=0.06$ in both cases). The results for CD83+ agree with those of Poindexter et al., who found a trend towards lower numbers of CD83+ in sentinel nodes with cancer than in tumour-free sentinel nodes [32].

\section{Macrophages}

Macrophages have dual roles [33]. M1 macrophages can phagocytize tumour cells and produce cytokines, such as prostaglandins and tumour necrosis factor-alpha $(\mathrm{TNF} \alpha)$, which may stimulate other potent immunological cells. M1 macrophages can also present tumour antigens to cytotoxic $\mathrm{T}$ cells. These factors favour an immunological response to tumour. M2 macrophages contribute to tumour progression by secretion of pro-angiogenic and anti-inflammatory mediators and growth factors and can suppress the antitumour immune response [34, 35]. These macrophages assist tumour progression [36]. Increased infiltration of tumour-associated M2 macrophages (TAMs) has been described as an indicator of poor prognosis in many malignant diseases [37].

ILT resulted in significantly increased numbers of macrophages within the tumour and at the tumour border. The macrophages in the core biopsies are probably both M1 and M2 subtypes, and our data do not allow any conclusion about the net effect of the anti-tumour and tumour progression activities following ILT [33]. Mantovani et al. suggested that the balance might be shifted towards antitumour activity if an acute inflammatory response is created [25]. Such an acute response is generated by ILT, which produces necrosis rather than apoptosis, and leakage of intracellular material, resulting in an inflammatory stimulus. It was recently reported that tumour cell death, induced by chemotherapy or radiotherapy, can activate tumour antigen presentation via antigen-presenting cells (APCs), resulting in increased treatment efficacy [38].

\section{T lymphocytes}

In our study, there were significantly more CD8 $+\mathrm{T}$ cells within the resected tumour after ILT than before treatment $(P<0.05)$ and there was a similar trend towards a higher number at the tumour border $(P=0.12)$. The CD8+ lymphocytes were seen within the tumour stroma and in some cases also within the tumour nests (Fig. 1). Intraepithelial infiltrates of CD8+ lymphocytes have been correlated with improved prognosis in several malignancies such as ovarian [39], cervical [40] and colorectal [41] cancer. A low $\mathrm{CD} 8+/ \mathrm{CD} 4+$ ratio has been suggested to worsen prognosis in patients with cervical cancer [42]. In the present study, there was a tendency towards higher CD8+/CD4+ ratios after ILT.

The finding of positive (myo)fibroblasts in the CD8 reaction is important. These cells are slender, while lymphocytes are round, and therefore easy to recognize in the microscope and delete from the counting of round lymphocytes.

Regulatory $T$ cells ( $T_{\text {reg }}$ cells)

There is substantial evidence that regulatory $T$ cells $\left(T_{\text {reg }}\right.$ cells) inhibit local anti-tumour immunity and that $T_{\text {reg }}$ cells mediate antigen-specific local suppression [43]. There are several subsets of $T_{\text {reg }}$ cells, and strong suppressive 
capacity is characterized by the CD25+ marker. Most $T_{\text {reg }}$ cells identified in human cancers belong to the CD4+ CD25+ Foxp3+ population. We studied the presence of CD25+ Foxp3+ cells, which left CD4+CD25-Foxp3+ cells undetected but included the majority of regulatory $\mathrm{T}$ cells [44].

$T_{\text {reg }}$ cells have been shown to infiltrate a number of cancers and metastatic lymph nodes, including breast [45, 46], ovarian [39, 47], cervical [42] and colorectal cancers [48, 49], and increase in $T_{\text {reg }}$ cells has been shown to correlate with worse prognosis. Two groups have demonstrated that a high CD8+/Foxp3+ ratio in the primary tumour seems to overcome the negative effects of regulatory $T$ cells in ovarian [47] and cervical [42] cancer.

After ILT, the number of $\mathrm{T}_{\text {regs }}$ within the resected tumour or at the tumour border did not change significantly, although there was a trend towards a decrease in CD25+ and CD25+Foxp3+ cells. However, in the lymph nodes without metastases, the ILT patients had a significantly lower number of CD25+Foxp3+ lymphocytes than the control patients (Fig. 5). This may indicate a favourable effect of ILT. It is interesting that Nakamura et al. [46] recently showed that elevated levels of $\mathrm{T}_{\text {regs }}$ in sentinel lymph nodes predict poor prognosis in node-negative breast cancer.

The reason for the increased density of CD20+ cells at the tumour border after ILT is unclear. The lowered presence of $T_{\text {reg }}$ cells may play a role since it has been shown that $T_{\text {reg }}$ cells can lyse antigen-presenting B cells [50].

\section{Conclusions}

Studies of gene expression profiles have demonstrated that there are several breast cancer subtypes with different behaviour, different prognosis and, probably, different immunological actions. It has, for instance, been shown that "triple negative" (ER-, PR-, HER2-) cancers, especially in combination with high grade, show features of immune tolerance, as indicated by increased infiltration of $T_{\text {reg }}$ cells in the tumour [51]. This and similar findings [52] highlight the importance of looking for molecular subtypes in breast cancer when exploring immunological effects of treatment.

In our study, the number of patients was low, and only two ILT patients were both ER- and PR-negative, which precluded evaluation of the role of different subtypes. Yet, ILT induced changes in immunocompetent cells in patients with breast cancer. ILT was followed by increases in CD8+ cytotoxic lymphocytes and mature CD83+ dendritic cells at the primary tumour and a decrease in CD25+Foxp3 $+T_{\text {reg }}$ lymphocytes in regional lymph nodes. Further work will help to clarify the role of ILT in breast cancer therapy.
Open Access This article is distributed under the terms of the Creative Commons Attribution Noncommercial License which permits any noncommercial use, distribution, and reproduction in any medium, provided the original author(s) and source are credited.

\section{References}

1. Muralidharan V, Christophi C (2001) Interstitial laser thermotherapy in the treatment of colorectal liver metastases. J Surg Oncol 76:73-81

2. Ruers TJ, Joosten J, Jager GJ, Wobbes T (2001) Long-term results of treating hepatic colorectal metastases with cryosurgery. Br J Surg 88:844-849

3. Tranberg KG (2004) Percutaneous ablation of liver tumours. Best Pract Res Clin Gastroenterol 18:125-145

4. Wu F, Wang ZB, Lu P, Xu ZL, Chen WZ, Zhu H, Jin CB (2004) Activated anti-tumor immunity in cancer patients after high intensity focused ultrasound ablation. Ultrasound Med Biol 30:1217-1222

5. Zerbini A, Pilli M, Penna A, Pelosi G, Schianchi C, Molinari A, Schivazappa S, Zibera C, Fagnoni FF, Ferrari C, Missale G (2006) Radiofrequency thermal ablation of hepatocellular carcinoma liver nodules can activate and enhance tumor-specific T-cell responses. Cancer Res 66:1139-1146

6. Dowlatshahi K, Dieschbourg JJ, Bloom KJ (2004) Laser therapy of breast cancer with 3-year follow-up. Breast J 10:240-243

7. Haraldsdóttir KH, Ivarsson K, Gotberg S, Ingvar C, Stenram U, Tranberg KG (2008) Interstitial laser thermotherapy (ILT) of breast cancer. Eur J Surg Oncol 34:739-745

8. Noguchi M, Earashi M, Fujii H, Yokoyama K, Harada K, Tsuneyama K (2006) Radiofrequency ablation of small breast cancer followed by surgical resection. J Surg Oncol 93:120-128

9. Sabel MS, Kaufman CS, Whitworth P, Chang H, Stocks LH, Simmons R, Schultz M (2004) Cryoablation of early-stage breast cancer: work-in-progress report of a multi-institutional trial. Ann Surg Oncol 11:542-549

10. Simmons RM (2003) Ablative techniques in the treatment of benign and malignant breast disease. J Am Coll Surg 197: 334-338

11. van der Ploeg IM, van Esser S, van den Bosch MA, Mali WP, van Diest PJ, Borel Rinkes IH, van Hillegersberg R (2007) Radiofrequency ablation for breast cancer: a review of the literature. Eur J Surg Oncol 33:673-677

12. Wu F, Wang ZB, Cao YD, Chen WZ, Bai J, Zou JZ, Zhu H (2003) A randomised clinical trial of high-intensity focused ultrasound ablation for the treatment of patients with localised breast cancer. Br J Cancer 89:2227-2233

13. Möller PH, Ivarsson K, Stenram U, Radnell M, Tranberg K-G (1997) Interstitial laser thermotherapy of an adenocarcinoma transplanted into rat liver. Eur J Surg 63:867-870

14. Wheatley DN, Kerr C, Gregory DW (1989) Heat-induced damage to HeLa-S3 cells: correlation of viability, permeability, osmosensitivity, phase-contrast light-, scanning electron- and transmission electron-microscopical findings. Int $\mathrm{J}$ Hyperthermia 5:145-162

15. Sturesson C, Ivarsson K, Andersson-Engels S, Tranberg K-G (1999) Changes in local hepatic blodd perfusion during interstitial laser-induced thermotherapy of normal rat liver measured by interstitial laser Doppler flowmetry. Lasers Med Sci 14:143-149

16. Ivarsson K, Myllymaki L, Jansner K, Bruun A, Stenram U, Tranberg KG (2003) Heat shock protein 70 (HSP70) after laser thermotherapy of an adenocarcinoma transplanted into rat liver. Anticancer Res 23:3703-3712

17. Ivarsson K, Myllymaki L, Jansner K, Stenram U, Tranberg KG (2005) Resistance to tumour challenge after tumour laser 
thermotherapy is associated with a cellular immune response. $\mathrm{Br}$ J Cancer 93:435-440

18. Möller PH, Ivarsson K, Stenram U, Radnell M, Tranberg K-G (1998) Comparison between interstitial laser thermotherapy and excision of an adenocarcinoma transplanted into rat liver. $\mathrm{Br} \mathbf{J}$ Cancer 77:1884-1892

19. Tranberg K-G, Ivarsson K, Sjögren H, Stenram U (2008) Laser thermotherapy of rat liver carcinoma increases anti-tumour lymphocyte responsiveness in tumour-draining and systemic lymph nodes and in spleen. HPB 10:10

20. Tranberg K-G, Ivarsson K, Willner J, Håkansson L, Stenram U (2002) Induction of a distant anti-tumour effect by interstitial laser thermotherapy (ILT) in a patient with malignant melanoma. In: Witz A (ed) Proc 2nd international conference on tumor microenvironment: progression, therapy and prevention. Baden, Austria, p 49

21. Isbert C, Ritz JP, Roggan A, Schuppan D, Ruhl M, Buhr HJ, Germer CT (2004) Enhancement of the immune response to residual intrahepatic tumor tissue by laser-induced thermotherapy (LITT) compared to hepatic resection. Lasers Surg Med 35:284-292

22. Tranberg K-G, Myllymäki L, Möller PH, Ivarsson K, Sjögren HO (2002) Interstitial laser thermotherapy of a rat liver adenocarcinoma. J X-ray Sci Technol 10:177-185

23. Gross S, Walden $P$ (2008) Immunosuppressive mechanisms in human tumors: why we still cannot cure cancer. Immunol Lett 116:7-14

24. Pardoll D (2003) Does the immune system see tumors as foreign or self? Annu Rev Immunol 21:807-839

25. Mantovani A, Romero P, Palucka AK, Marincola FM (2008) Tumour immunity: effector response to tumour and role of the microenvironment. Lancet 371:771-783

26. Shi Y, Zheng W, Rock KL (2000) Cell injury releases endogenous adjuvants that stimulate cytotoxic $\mathrm{T}$ cell responses. Proc Natl Acad Sci USA 97:14590-14595

27. Bell D, Chomarat P, Broyles D, Netto G, Harb GM, Lebecque S, Valladeau J, Davoust J, Palucka KA, Banchereau J (1999) In breast carcinoma tissue, immature dendritic cells reside within the tumor, whereas mature dendritic cells are located in peritumoral areas. J Exp Med 190:1417-1426

28. Hillenbrand EE, Neville AM, Coventry BJ (1999) Immunohistochemical localization of CD1a-positive putative dendritic cells in human breast tumours. Br J Cancer 79:940-944

29. Iwamoto M, Shinohara H, Miyamoto A, Okuzawa M, Mabuchi H, Nohara T, Gon G, Toyoda M, Tanigawa N (2003) Prognostic value of tumor-infiltrating dendritic cells expressing CD83 in human breast carcinomas. Int J Cancer 104:92-97

30. Miyagawa S, Soeda J, Takagi S, Miwa S, Ichikawa E, Noike T (2004) Prognostic significance of mature dendritic cells and factors associated with their accumulation in metastatic liver tumors from colorectal cancer. Hum Pathol 35:1392-1396

31. Somersan S, Larsson M, Fonteneau JF, Basu S, Srivastava P, Bhardwaj N (2001) Primary tumor tissue lysates are enriched in heat shock proteins and induce the maturation of human dendritic cells. J Immunol 167:4844-4852

32. Poindexter NJ, Sahin A, Hunt KK, Grimm EA (2004) Analysis of dendritic cells in tumor-free and tumor-containing sentinel lymph nodes from patients with breast cancer. Breast Cancer Res 6:R408-R415

33. Allavena P, Sica A, Garlanda C, Mantovani A (2008) The YinYang of tumor-associated macrophages in neoplastic progression and immune surveillance. Immunol Rev 222:155-161

34. Leek RD, Harris AL (2002) Tumor-associated macrophages in breast cancer. J Mammary Gland Biol Neoplasia 7:177-189

35. Wyckoff JB, Wang Y, Lin EY, Li JF, Goswami S, Stanley ER, Segall JE, Pollard JW, Condeelis J (2007) Direct visualization of macrophage-assisted tumor cell intravasation in mammary tumors. Cancer Res 67:2649-2656

36. Lin EY, Pollard JW (2007) Tumor-associated macrophages press the angiogenic switch in breast cancer. Cancer Res 67:5064-5066

37. Chen JJ, Lin YC, Yao PL, Yuan A, Chen HY, Shun CT, Tsai MF, Chen CH, Yang PC (2005) Tumor-associated macrophages: the double-edged sword in cancer progression. J Clin Oncol 23:953-964

38. Apetoh L, Ghiringhelli F, Tesniere A, Obeid M, Ortiz C, Criollo A, Mignot G, Maiuri MC, Ullrich E, Saulnier P, Yang H, Amigorena S, Ryffel B, Barrat FJ, Saftig P, Levi F, Lidereau R, Nogues C, Mira JP, Chompret A, Joulin V, Clavel-Chapelon F, Bourhis J, Andre F, Delaloge S, Tursz T, Kroemer G, Zitvogel L (2007) Toll-like receptor 4-dependent contribution of the immune system to anticancer chemotherapy and radiotherapy. Nat Med 13:1050-1059

39. Sato E, Olson SH, Ahn J, Bundy B, Nishikawa H, Qian F, Jungbluth AA, Frosina D, Gnjatic S, Ambrosone C, Kepner J, Odunsi T, Ritter G, Lele S, Chen YT, Ohtani H, Old LJ, Odunsi K (2005) Intraepithelial CD8+ tumor-infiltrating lymphocytes and a high CD8+/regulatory $\mathrm{T}$ cell ratio are associated with favorable prognosis in ovarian cancer. Proc Natl Acad Sci USA 102:18538-18543

40. Nedergaard BS, Ladekarl M, Thomsen HF, Nyengaard JR, Nielsen K (2007) Low density of CD3+, CD4+ and CD8+ cells is associated with increased risk of relapse in squamous cell cervical cancer. Br J Cancer 97:1135-1138

41. Pagés F, Berger A, Camus M, Sanchez-Cabo F, Costes A, Molidor R, Mlecnik B, Kirilovsky A, Nilsson M, Damotte D, Meatchi T, Bruneval P, Cugnenc PH, Trajanoski Z, Fridman WH, Galon J (2005) Effector memory T cells, early metastasis, and survival in colorectal cancer. N Engl J Med 353:2654-2666

42. Piersma SJ, Jordanova ES, van Poelgeest MI, Kwappenberg KM, van der Hulst JM, Drijfhout JW, Melief CJ, Kenter GG, Fleuren GJ, Offringa R, van der Burg SH (2007) High number of intraepithelial CD8+ tumor-infiltrating lymphocytes is associated with the absence of lymph node metastases in patients with large early-stage cervical cancer. Cancer Res 67:354-361

43. Wang HY, Wang RF (2007) Regulatory T cells and cancer. Curr Opin Immunol 19:217-223

44. Roncador G, Brown PJ, Maestre L, Hue S, Martinez-Torrecuadrada JL, Ling KL, Pratap S, Toms C, Fox BC, Cerundolo V, Powrie F, Banham AH (2005) Analysis of FOXP3 protein expression in human $\mathrm{CD} 4+\mathrm{CD} 25+$ regulatory $\mathrm{T}$ cells at the single-cell level. Eur J Immunol 35:1681-1691

45. Bates GJ, Fox SB, Han C, Leek RD, Garcia JF, Harris AL, Banham AH (2006) Quantification of regulatory T cells enables the identification of high-risk breast cancer patients and those at risk of late relapse. J Clin Oncol 24:5373-5380

46. Nakamura R, Sakakibara M, Nagashima T, Sangai T, Arai M, Fujimori T, Takano S, Shida T, Nakatani Y, Miyazaki M (2009) Accumulation of regulatory $\mathrm{T}$ cells in sentinel lymph nodes is a prognostic predictor in patients with node-negative breast cancer. Eur J Cancer 45:2123-2131

47. Curiel TJ, Coukos G, Zou L, Alvarez X, Cheng P, Mottram P, Evdemon-Hogan M, Conejo-Garcia JR, Zhang L, Burow M, Zhu Y, Wei S, Kryczek I, Daniel B, Gordon A, Myers L, Lackner A, Disis ML, Knutson KL, Chen L, Zou W (2004) Specific recruitment of regulatory $\mathrm{T}$ cells in ovarian carcinoma fosters immune privilege and predicts reduced survival. Nat Med 10:942-949

48. Chaput N, Louafi S, Bardier A, Charlotte F, Vaillant JC, Menegaux F, Rosenzwajg M, Lemoine F, Klatzmann D, Taieb J (2009) Identification of CD8+CD25+Foxp3+ suppressive T cells in colorectal cancer tissue. Gut 58:520-529 
49. Sinicrope FA, Rego RL, Ansell SM, Knutson KL, Foster NR, Sargent DJ (2009) Intraepithelial effector (CD3+)/regulatory (FoxP3+) T-cell ratio predicts a clinical outcome of human colon carcinoma. Gastroenterology 137:1270-1279

50. Janssens W, Carlier V, Wu B, VanderElst L, Jacquemin MG, Saint-Remy JM (2003) CD4+CD25+ T cells lyse antigen-presenting B cells by Fas-Fas ligand interaction in an epitope-specific manner. J Immunol 171:4604-4612
51. Bohling SD, Allison KH (2008) Immunosuppressive regulatory T cells are associated with aggressive breast cancer phenotypes: a potential therapeutic target. Mod Pathol 21:1527-1532

52. Ghebeh H, Barhoush E, Tulbah A, Elkum N, Al-Tweigeri T, Dermime S (2008) FOXP3+ Tregs and B7-H1+/PD-1+ T lymphocytes co-infiltrate the tumor tissues of high-risk breast cancer patients: implication for immunotherapy. BMC Cancer $8: 57$ 